\title{
Epigenetic Modifications the Development of Different Heart Failure Phenotypes
}

\section{Alexander E Berezin}

Internal Medicine Department, State Medical University, Mayakovsky Av., Zaporozhye, Ukraine

*Corresponding author: Alexander E Berezin, Consultant of Cardiology Unit, Internal Medicine Department, State Medical University, Mayakovsky Av., Zaporozhye, Ukraine, Tel: +380612894585; E-mail: dr_berezin@mail.ru

Received date: May 20, 2016; Accepted date: June 21, 2016; Published date: June 27, 2016

Copyright: ( 2016 Berezin AE. This is an open-access article distributed under the terms of the Creative Commons Attribution License, which permits unrestricted use, distribution, and reproduction in any medium, provided the original author and source are credited.

\begin{abstract}
Heart failure (HF) remains a leading cause of death in patient population with known cardiovascular disease. Within last two decades there are evidences regarding decline to determine newel cases with HF with reduced ejection fraction (HFrEF) in developed countries, whereas the frequency of newly-diagnosed HF with preserved ejection fraction (HFpEF) exhibits dramatically rise. Epigenetic modification is considered a modification of the nonDNA sequences related heritable changes in gene expression of target cells. Epigenetic modifications affect several molecular mechanisms, i.e., DNA methylation and deactylation, ATP-dependent chromatin remodeling, histone modifications, and microRNA regulation. The short commentary is clarified the implication of epigenetic modifications in development of different HF phenotypes.
\end{abstract}

Keywords: Heart failure; Heart failure with preserved ejection fraction; Heart failure with reduced ejection fraction; Epigenetics

\section{Short Communication}

Heart failure (HF) is a sufficient medical problem and social burden that associates with increased morbidity/mortality rate and disability rate in the developed countries [1]. Within last decades there is progressively decrease of prevalence of $\mathrm{HF}$ with reduced left ventricular ejection fraction (HFrEF) [2]. In opposite, the frequency of newly-diagnosed HF with preserved left ventricular ejection fraction (HFpEF) appears to be raised [3]. These changes in presentation of HF phenotypes might relate to advance in contemporary of HF medical care [4], impact of age-related comorbidities and socioeconomic status [5-8]. Despite the implementation in routine clinical practice modern pharmacological strategy and none-drug therapy including implanted devices for mechanical support and pacing [8-10], the clinical outcomes in subjects with HFrEF and HFpEF remain similar [11].

In this context, the discovery of several biomarkers reflecting various pathophysiological stages of HF appears to be promised. Currently available clinical guidelines have been recommended to use a limited numerous of biomarkers for risk stratification of the patients with of HF (brain natriuretic peptides, soluble ST2, galectin-3, and higher sensitive cardiac troponins). However, not all these biomarkers have exhibited higher predictive value of manifestation and development of HFpEF $[4,12,13]$. Interestingly, the most biomarkers are considered a prognosticators in symptomatic patients with known HFpEF or HFrEF, but their role in concerning the risk of $\mathrm{HF}$ development in individuals at higher risk of cardiac dysfunction is not yet clear [14]. It is suggested that the age-related co- morbidities and ischemic/non-ischemic etiology are the factors, which might sufficiently limit both diagnostic and predictive utility of currently used biological markers [15].

Recent studies have shown the pivotal role of cardiovascular remodeling, immune dysfunction, low-grade microvascular inflammation, hypercoagulation/thrombosis, endothelial dysfunction, autonomic nervous system and neurohumoral abnormalities in the pathogenesis of HF beyond initially occurred etiology factors [16,17]. However, both HF phenotypes may distinguish in etiological factors (ischemic/none-ischemic), aging (older vs. younger) and sex presentation, pre-existing co-morbidities (i.e., hypertension, lung and rheumatic disease, diabetes, obesity), as well as predominantly intracellular mechanisms, which are involved in the pathogenesis of cardiac dysfunction. There is not only hypothetically possibilities, but large body of evidence with respect to the tremendous impact of epigenetic modifications (i.e., DNA and histone modifications, ATPdependent chromatin remodeling, and microRNA-related signals and processes) on phenotypic response regarding failing heart and leading to form either HFrEF, or HFpEF $[18,19]$.

Theoretically, the post-translational modification of DNA may link chromatin repair, transcription, translation, cell signaling, and cell death in the failing heart specifically mediating phenotypic response neither HFrEF, or HFpEF. Various reprogramming of gene expression, including downregulation of the alpha-myosin heavy chain gene, homeobox gene Pitx $2 c$, angiotensin II gene, cardiac troponin $\mathrm{T}$ gene, cardiac actin and myosin binding protein $\mathrm{C}$ genes, alpha-tropomyosin and myosin light chains genes, sarcoplasmic reticulum $\mathrm{Ca} 2+$ ATPase genes, estrogen receptor-alpha, estrogen receptor-beta and reactivation of specific fetal cardiac genes including atrial and brain natriuretic peptides are involved in the phenotypic response in failing heart $[19,20]$.

Recent animal studies have shown that histones acetylation/ methylation rather DNA modification could be the important mechanisms of epigenetics determined failing heart response through miRNA signaling [21,22]. Indeed, sirtuins have been involved into DNA damage reparation, inhibition of inflammation and fibrosis [23]. Down-regulated sirtuin-1, sirtuin-2, situin-3 and sirtuin-6 have been implicated in the cell death/survival process, oxidative stress, sensitivity to ischemic injury, and they may induce cardiac hypertrophy, accumulation of extra cellular collagens, microvascular 
Page 2 of 3

inflammation [21]. All these factors contribute to failing heart development and may mediate HFpEF [24]. The nicotinamide adenine dinucleotide-dependent histone deacetylase (HDAC) was found as a regulator of cellular processes, including gene silencing, longevity, and DNA damage repair. In animals the inhibition of endogenous HDACII has primarily caused cardiac myocyte hypertrophy and also induced modest cell death [22]. In contrast, inhibition of class I HDACs presented anti-hypertrophic effect [25]. Moreover, induced expression of class II HDAC in cardiomyocytes mimics hypertrophic growth in an Akt-dependent manner [26].

In clinical settings it has found a sufficient difference in DNA methylation in promoters of up-regulated genes, but not downregulated genes in severe HF [27]. Xiao et al. [28] reported that increased DNA methylation might have a causative role in programming of heart hypertrophy and reduced global cardiac contractility function. Probably epigenetic modifications identified in failing heart might affect cardiac function directly through regulation of structure protein synthesis and indirectly via increased activity of cardiac fibroblasts. However, the role of DNA methylation in the development of both phenotypes of HF beyond inhered forms is not yet clear.

The ATP-dependent chromatin remodeling complexes are not able to directly modify DNA or histones, whereas they may use energy of ATP hydrolysis in processes regarding destabilize, eject or restructure of nucleosomes and play a pivotal role in HF development [29]. Several triggers including metabolic factors, aging, oxidative stress, and hemodynamic stress may impact on the HF phenotype presentation through ATP-dependent chromatin remodeling-depended mechanisms.

Histone modification represents a dynamic process affected histone proteins that are composed in the nucleosomes and mediated by several enzymes [30]. Recent studies have shown that histone modification predominantly methylation is closely regulates inflammatory and metabolic disorders, as well as links CV disease and vascular homeostasis [31]. There is evidence that altered redox signaling might mediate trimethylation of histones and links an oxidative stress pathway with biochemical mechanisms underlying HFrEF development [32].

MicroRNAs (miRNAs) are small non-coding RNAs that exert their function by both transcript degradation and translational inhibition, resulting in changes in target genes and proteins' expression [33]. It has been suggested that reactivation of a fetal microRNA program substantially contributes to alterations of gene expression in the failing human heart. The recent studies have shown that the increased expression of miRNA-1, miRNA-21, miRNA-29b, miRNA-129, miRNA-133, miRNA-208, miRNA-210, miRNA-211, miRNA-212, and miRNA-423, and miRNA-499 miRNA503 [34]. Theoretically, there is well-described signature of cardiac-specific miRNAs, which may involve in cardiac remodeling forming HF phenotypes [35]. On this way, signature of miRNA expression (especially miRNA-7, miRNA-123, miRNA-378) has been allowed to differ healthy and failing hearts and depended on reactivation of a fetal gene program. Indeed, these miRNAs have been displayed different expression levels in HF at early and end stage failing hearts [36]. However, low number of direct clinical evidence regarding specifically HF phenotypes' development relating to miRNA signature remains a part of scientific discussion [37].

\section{Conclusion}

In conclusion, the current available data preliminary clarify that epigenetic modifications might be discussed as a key factor forming different phenotypes in HF, whereas there is no strong evidence regarding epigenetic signatures represent causal pathways leading to specific forms of cardiac remodeling associated with HFrEF or HFpEF.

\section{Acknowledgement}

This research received no specific grant from any funding agency in the public, commercial, or not-for-profit sectors.

\section{References}

1. van Riet EE, Hoes AW, Wagenaar KP, Limburg A, Landman MA, et al. (2016) Epidemiology of heart failure: the prevalence of heart failure and ventricular dysfunction in older adults over time. A systematic review. Eur J Heart Fail 18: 242-252.

2. Jorge AL, Rosa ML, Martins WA, Correia DM, Fernandes LC, et al. (2016) The Prevalence of Stages of Heart Failure in Primary Care: A Population-Based Study. J Card Fail 22: 153-157.

3. Banerjee P (2016) Heart failure with preserved ejection fraction: A clinical crisis. Int J Cardiol 204: 198-199.

4. Yancy CW, Jessup M, Bozkurt B, Butler J, Casey DE, et al. (2013) ACCF/AHA guideline for the management of heart failure: A report of the American College of Cardiology Foundation/American Heart Association Task Force on Practice Guidelines. J Am Coll Cardiol 62: e147-e239.

5. Buja A, Solinas G, Visca M, Federico B, Gini R, et al. (2016) Prevalence of Heart Failure and Adherence to Process Indicators: Which SocioDemographic Determinants are Involved? Int J Environ Res Public Health 13: 238.

6. Kosiborod M, Lichtman JH, Heidenreich PA, Normand SL, Wang Y, et al. (2006) National trends in outcomes among elderly patients with heart failure. Am J Med 119: 616.

7. Frankenstein L, Clark AL, Ribeiro JP (2012) Influence of sex on treatment and outcome in chronic heart failure. Cardiovasc Ther 30: 182-192.

8. Rathore SS, Masoudi FA, Wang Y, Curtis JP, Foody JM, et al. (2006) Socioeconomic status, treatment, and outcomes among elderly patients hospitalized with heart failure: Findings from the National Heart Failure Project. Am Heart J 152: 371-378.

9. Brouwers FP, de Boer RA, van der Harst P, Voors AA, Gansevoort RT, et al. (2013) Incidence and epidemiology of new onset heart failure with preserved vs. reduced ejection fraction in a community-based cohort: 11year follow-up of PREVEND. Eur Heart J 34: 1424-1431.

10. Hawkins NM, Virani SA, Sperrin M, Buchan IE, McMurray JJ, et al. (2015) Predicting heart failure decompensation using cardiac implantable electronic devices: a review of practices and challenges. Eur J Heart Fail.

11. McMurray JJ (2015) Improving outcomes in heart failure: a personal perspective†. Eur Heart J 36: 3467-3470.

12. McMurray JJ, Adamopoulos S, Anker SD, Auricchio A, Bohm M, et al. (2012) ESC guidelines for the diagnosis and treatment of acute and chronic heart failure 2012: The Task Force for the Diagnosis and Treatment of Acute and Chronic Heart Failure 2012 of the European Society of Cardiology. Developed in collaboration with the Heart Failure Association (HFA) of the ESC. Eur J Heart Fail 14: 803-869.

13. Butler J, Fonarow GC, Zile MR, Lam CS, Roessig L, et al. (2014) Developing therapies for heart failure with preserved ejection fraction: current state and future directions. JACC Heart Fail 2: 97-112.

14. D'Elia E, Vaduganathan M, Gori M, Gavazzi A, Butler J, et al. (2015) Role of biomarkers in cardiac structure phenotyping in heart failure with preserved ejection fraction: critical appraisal and practical use. Eur J Heart Fail. 
Citation: Berezin AE (2016) Epigenetic Modifications the Development of Different Heart Failure Phenotypes. J Data Mining Genomics \&

Page 3 of 3

15. Chamberlain AM, St Sauver JL, Gerber Y, Manemann SM, Boyd CM, et al. (2015) Multimorbidity in heart failure: a community perspective. Am J Med 128: 38-45

16. Paulus WJ, Tschöpe C (2013) A novel paradigm for heart failure with preserved ejection fraction: comorbidities drive myocardial dysfunction and remodeling through coronary microvascular endothelial inflammation. J Am Coll Cardiol 62: 263-271.

17. Berezin A (2015) Endothelial Derived Micro Particles: Biomarkers for Heart Failure Diagnosis and Management. J Clin Trial Cardiol 2: 1-3.

18. Napoli C, Grimaldi V, De Pascale MR, Sommese L, Infante T, et al. (2016) Novel epigenetic-based therapies useful in cardiovascular medicine. World J Cardiol 8: 211-219.

19. Di Salvo TG, Haldar SM (2014) Epigenetic mechanisms in heart failure pathogenesis. Circ Heart Fail 7: 850-863.

20. Kao YH, Chen YC, Chung CC, Lien GS, Chen SA, et al. (2013) Heart failure and angiotensin II modulate atrial Pitx $2 c$ promotor methylation. Clin Exp Pharmacol Physiol 40: 379-384.

21. Matsushima S, Sadoshima J (2015) The role of sirtuins in cardiac disease. Am J Physiol Heart Circ Physiol 309: H1375-1389.

22. Alcendor RR, Kirshenbaum LA, Imai S, Vatner SF, Sadoshima J (2004) Silent information regulator 2alpha, a longevity factor and class III histone deacetylase, is an essential endogenous apoptosis inhibitor in cardiac myocytes. Circ Res 95: 971-980.

23. Kitada M, Kume S, Takeda-Watanabe A, Kanasaki K, Koya D (2013) Sirtuins and renal diseases: relationship with aging and diabetic nephropathy. Clin Sci (Lond) 124: 153-164.

24. Vakhrusheva O, Smolka C, Gajawada P, Kostin S, Boettger T, et al. (2008) Sirt7 increases stress resistance of cardiomyocytes and prevents apoptosis and inflammatory cardiomyopathy in mice. Circ Res 102: 703-710.

25. Teperino R, Schoonjans K, Auwerx J (2010) Histone methyl transferases and demethylases; can they link metabolism and transcription? Cell Metab 12: 321-327.

26. Kee HJ, Sohn IS, Nam KI, Park JE, Qian YR, et al. (2006) Inhibition of histone deacetylation blocks cardiac hypertrophy induced by angiotensin II infusion and aortic banding. Circulation 113: 51-59.
27. Movassagh M, Choy MK, Knowles DA, Cordeddu L, Haider S, et al (2011) Distinct epigenomic features in end-stage failing human hearts. Circulation 124: 2411-2422.

28. Xiao D, Dasgupta C, Chen M, Zhang K, Buchholz J, et al. (2014) Inhibition of DNA methylation reverses norepinephrine-induced cardiac hypertrophy in rats. Cardiovasc Res 101: 373-382.

29. Lange M, Demajo S, Jain P, Di Croce L (2011) Combinatorial assembly and function of chromatin regulatory complexes. Epigenomics 3: 567-580.

30. Zhang Y, Fatima N, Dufau ML (2005) Coordinated changes in DNA methylation and histone modifications regulate silencing/derepression of luteinizing hormone receptor gene transcription. Mol Cell Biol 25: 7929-7939.

31. Shi Y, Whetstine JR (2007) Dynamic regulation of histone lysine methylation by demethylases. Mol Cell 25: 1-14.

32. Kim GH, Ryan JJ, Archer SL (2013) The role of redox signaling in epigenetics and cardiovascular disease. Antioxid Redox Signal 18: 1920-1936.

33. Ambros V (2001) microRNAs: tiny regulators with great potential. Cell 107: 823-826.

34. van Rooij E, Sutherland LB, Liu N, Williams AH, McAnally J, et al. (2006) A signature pattern of stress-responsive microRNAs that can evoke cardiac hypertrophy and heart failure. Proc Natl Acad Sci USA 103: 18255-18260.

35. Bagnall RD, Tsoutsman T, Shephard RE, Ritchie W, Semsarian C (2012) Global microRNA profiling of the mouse ventricles during development of severe hypertrophic cardiomyopathy and heart failure. PLoS One 7: e44744.

36. Naga Prasad SV, Duan ZH, Gupta MK, Surampudi VS, Volinia S, et al. (2009) Unique microRNA profile in end-stage heart failure indicates alterations in specific cardiovascular signaling networks. J Biol Chem 284: 27487-27499.

37. Berezin A (2016) Impaired Phenotype of Endothelial Cell-Derived Micro Particles: The Missed Link in Heart Failure Development?. Biomark J 2: 14-19. 